\title{
Severe Delayed Hypersensitivity Reaction to Abiraterone Acetate
}

Lainez-Nuez $\mathrm{A}^{1,2 *}$, Crespo $\mathrm{J}^{1,2 *}$, Noguerado-Mellado $\mathrm{B}^{1,2}$, TejeroAlcalde $\mathrm{M}^{1,2}$, Tornero $\mathrm{P}^{1,2}$, Rojas-Pérez-Ezquerra $\mathrm{P}^{1,2}$

${ }^{1}$ Allergy Department, University Hospital Gregorio Marañon, Madrid, Spain

${ }^{2}$ Gregorio Marañón Health Research Institute, Madrid, Spain

*These authors contributed equally to this work.

J Investig Allergol Clin Immunol 2021; Vol. 31(2): 168-170 doi: 10.18176/jiaci.0560

Key words: Abiraterone. Delayed hypersensitivity reaction. Exanthema. Pregnenolone. Skin tests.

Palabras clave: Abiraterona. Reacción de hipersensibilidad tardía. Exantema. Pregnenolona. Pruebas cutáneas.

Prostate cancer $(\mathrm{PCa})$ is among the most common cancers in men worldwide [1]. While androgen deprivation therapy has been the standard of care for initial management of advanced or metastatic $\mathrm{PCa}$, progression to castration-resistant $\mathrm{PCa}$ occurs within 2 or 3 years after initiation. Newer agents target some of these mechanisms of resistance and provide an additional survival benefit $[2,3]$. These include abiraterone acetate (AA), which interferes with androgenic stimulation of the growth of PCa, and pembrolizumab, an immune checkpoint inhibitor [4]. Allergic reactions to medications are unexpected and lifethreatening and may necessitate therapeutic alternatives, which in some cases obviate the need for first-line therapies, with the consequent impact on survival and quality of life [5].

We report the case of a 47-year-old man diagnosed in 2016 with stage IV PCa (Gleason 8), accompanied by lymph node and bone involvement. The patient completed treatment with oral bicalutamide, intravenous leuprorelin acetate, and 6 cycles of docetaxel in 2017. Treatment induced a biochemical response, and lymph nodes had almost returned to normal size, with sclerotic changes in lytic bone metastases. In September 2019, owing to biochemical progression, he started treatment with oral AA $500 \mathrm{mg}$ taken as 2 tablets once daily (combined with oral prednisone $5 \mathrm{mg} / 12 \mathrm{~h}$ in order to prevent the increase in mineralocorticosteroids caused by its mechanism of action [6]) and intravenous pembrolizumab $200 \mathrm{mg}$ every 3 weeks. Ten days after the beginning of this regimen, the patient developed a symmetrically distributed and very pruriginous morbilliform exanthem on the trunk, groins, and root of the upper and lower limbs. He attended the emergency department with extreme weakness, nausea, vomiting, and fever of $38.8^{\circ} \mathrm{C}$, accompanied by skin lesions. His blood count and hepatic and renal profile were normal. He also reported an infectious environment at home (his child had acute gastroenteritis), leading his oncologist to suspect a viral condition and treat him with oral paracetamol. Evaluation 2 days later in the emergency department revealed pharyngeal hyperemia, enanthema, and progression of the exanthem 
over the back, root of the lower limbs, and arms in the form of a confluent, erythematous, purplish rash, with lingual, labial, and palpebral edema. Fever up to $38^{\circ} \mathrm{C}$ also persisted, despite treatment with paracetamol. Blood tests showed neither eosinophilia nor alteration of liver or kidney function. Serological tests for Epstein-Barr virus, cytomegalovirus, HIV, parvovirus B19, measles, Mycoplasma, and hepatitis $\mathrm{C}$ virus yielded negative results. Antineoplastic treatment was interrupted, oral methylprednisolone $40 \mathrm{mg} / 24 \mathrm{~h}$ was prescribed in tapering doses, and oral dexchlorpheniramine 2 $\mathrm{mg} / 8 \mathrm{~h}$ was prescribed for 14 days. The exanthem resolved 1 week later, with no desquamation or residual lesions.

The patient was assessed in our Allergy Department because his oncologist wanted to continue with AA. As a viral condition was suspected and standardized skin tests (skin prick test [SPT] and intradermal tests [IDT]) with AA and pembrolizumab are scarce (only a few cases have been reported in the literature), we obtained the patient's informed consent to perform a single-blind oral challenge test (SBOCT) with AA over 2 days in order to achieve a total dose of $1000 \mathrm{mg}$. On the first day, 4 hours after administration of $250 \mathrm{mg}$ of AA (with prednisone $5 \mathrm{mg}$ ), the patient developed pruriginous erythema on the chest, bilateral palpebral edema, and a peak fever of $38^{\circ} \mathrm{C}$. The reaction was treated with oral paracetamol $1000 \mathrm{mg}$, subcutaneous dexchlorpheniramine 5 $\mathrm{mg}$, and intramuscular methylprednisolone $60 \mathrm{mg}$ and resolved in 24 hours. Neither eosinophilia nor impaired liver or kidney function were observed in this episode.

After analyzing the reaction, we considered the possibility of desensitization with AA. However, given the intense cutaneous reaction and several general symptoms (drug fever), we decided to contraindicate desensitization, as reported in the literature [7]. Administration of AA and other pregnenolone analogues was subsequently forbidden.

In order to continue with first-line therapy, a single blinded intravenous challenge test was performed with $200 \mathrm{mg}$ of pembrolizumab diluted in $200 \mathrm{~mL}$ of saline solution in 4 hours, and the patient did not develop symptoms in the following 24 hours. Therefore, treatment with pembrolizumab was subsequently administered at the usual dose. Finally, the patient was diagnosed with delayed hypersensitivity reaction to AA.

AA is an orally administered, selective androgen synthesis inhibitor, which has demonstrated efficacy and significantly increased survival in men with metastatic castration-resistant $\mathrm{PCa}$ who had previously received docetaxel [2,3]. It is administered in combination with corticosteroids to prevent drug-induced hyperaldosteronism [6]. Its common adverse effects include hypertension, hypokalemia, hepatotoxicity, peripheral edema, and urinary tract infection $[4,6]$. However, hypersensitivity reactions are infrequent, and only a few cases have been reported in the literature [8,9]. In 2018, Verdu et al [8] reported the case of a patient who experienced immediate generalized urticaria to AA. The authors performed rapid desensitization, but without previous skin testing or graded challenge; therefore, the underlying hypersensitivity mechanism was unknown. Núñez-Acevedo et al [9] reported a delayed mild maculopapular rash in a patient treated with AA. SPT was carried out at $200 \mathrm{mg} / \mathrm{mL}$, although the results were negative. In nonimmediate reactions, we suggest that delayed IDT could have been the most sensitive method for elucidating the mechanism of the reaction [10], even though a standardized concentration of IDT has not yet been published in the literature. Nevertheless, SBOCT yielded a positive result, and a successful desensitization protocol was performed on consecutive days.

Little is known about desensitization in delayed hypersensitivity reactions [7]. Maculopapular exanthems are the only delayed reactions that have been well studied and successfully desensitized. When systemic symptoms are present, desensitization is not recommended and may be absolutely contraindicated if there are severe cutaneous adverse reactions [7]. Given the presence of drug-induced fever and generalized skin reaction with angioedema in the case we report, we finally considered desensitization to be contraindicated.

In conclusion, we present the case of a delayed systemic reaction to AA in a patient whose allergy was confirmed with SBOCT. Unfortunately, as the patient could not be desensitized, AA was forbidden, thus entailing a risk of failing treatment for PCa. More studies should be performed on the standardization of skin and in vitro tests for complete and appropriate allergy work-up. Such an approach could help us to understand the hypersensitivity mechanism beyond the reaction and, consequently, enable us to tailor management.

\section{Funding}

The study was funded by the Spanish National Health System.

\section{Conflicts of Interest}

The authors declare that they have no conflicts of interest.

\section{References}

1. Ferlay, J, Soerjomataram I, Dikshit R, Eser S, Mathers C, Rebelo $\mathrm{M}$, et al. Cancer incidence and mortality worldwide: sources, methods and major patterns in GLOBOCAN 2012. Int J Cancer. 2015;136:E359.

2. Chandrasekar T, Yang JC, Gao AC, Evans CP. Mechanisms of resistance in castration-resistant prostate cancer. Transl Androl Urol. 2015;4:365-80.

3. Hoy SM. Abiraterone acetate: a review of its use in patients with metastatic castration-resistant prostate cancer. Drugs. 2013;73:2077-91.

4. Spain L, Diem S, Larkin J. Management of toxicities of immune checkpoint inhibitors. Cancer Treatment Reviews. 2016;44:5160.

5. Castells MC. Rapid Drug Desensitization for Hypersensitivity Reactions to Chemotherapy and Monoclonal Antibodies in the 21st Century. J Investig Allergol Clin Immunol. 2014;24:72-9.

6. Fizazi K, Tran N, Fein L, Matsubara N, Rodríguez-Antolin A, Alekseyev BY, et al. Abiraterone plus prednisone in metastatic, castration-sensitive prostate cancer. N Eng J Med. 2017;377:352-60.

7. Scherer K, Brockow K, Aberer W, Gooi JH, Demoly P, Romano $A$, et al. Desensitization in delayed drug hypersensitivity 
reactions - an EAACl position paper of the Drug Allergy Interest Group. Allergy. 2013;68:844-52.

8. Verdú M, Torres-Degayon V, Hassan-Bennis M. Rapid oral desensitization protocol to abiraterone acetate. Ann Allergy Asthma Immunol. 2018;120(6):661-71.

9. Núñez-Acevedo $B$, Rubio-Pérez $M$, Padial-Vilchez $A$, de la Morena-Gallego JM, Barro-Ordovás JP, Reche Frutos M, et al. Safe and Successful Protocol for Desensitization to Abiraterone. J Investig Allergol Clin Immunol. 2019;29:38687.

10. Philips EJ, Bigliardi P, Bircher AJ, Broyles A, Chang YS, Chung $\mathrm{WH}$, et al. Controversies in drug allergy: Testing for delayed reactions. J Allergy Clin Immunol. 2019;143:66-73.

Manuscript received April 23, 2020; accepted for publication July 25, 2020.

\section{Patricia Rojas-Perez-Ezquerra}

Allergy Department

Hospital General Universitario Gregorio Marañón

Dr Esquerdo, 46

28007 Madrid, Spain

E-mail: patricia.rojas@salud.madrid.org 